\title{
El Carácter Evolutivo de los Retos de la Sociedad Civil
}

\author{
José G. Vargas-Hernández*
}

Este trabajo tiene por objetivo analizar el carácter evolutivo de la sociedad civil a partir de su conceptualización, orientación como forma de gobernancia y la delimitación de las características propias de la comunidad, mercado, Estado y sociedad civil como tipos ideales de orden social. El análisis de las funciones de la sociedad civil permiten determinar como una tendencia la emergencia en Latinoamérica. Finalmente, se analizan los retos que enfrenta la sociedad civil.

Palabras clave: Comunidad, Estado, forma de gobernancia, mercado, sociedad civil

Este trabalho tem como objetivo analisar a natureza evolutiva da sociedade civil a partir de sua conceituação, como uma forma de orientação de governo e do delineamento das características da sociedade da

\section{concepto de sociedad civil}

Ta definición o el concepto de sociedad civil implica recurrir a referencias filosóficas, económicas, políticas, sociales, culturales, históricas, funcionales, etc. El concepto de sociedad civil es práctico indicativo que engloba a todas las instituciones y mecanismos que no forman parte del Estado, de acuerdo a Anderson. En un concepto más amplio, la sociedad civil comprende a las diversas instituciones sociales, económicas del mercado, la

\footnotetext{
* M B.A.; PhD. Profesor Investigador miembro del Sistema Nacional de Investigadores. Departamento de Mercadotecnia y Negócios Internacionales. Centro Universitário de Ciencias Econômico Administrativas. Universidade de Guadalajara. Periférico Norte 799 Edificio G-306, Zapopan, Jalisco, C. P. 45100, México. Tel y fax: +52 (33) 3770
} 
comunidade, estado, mercado e civil como tipos ideais de ordem social. A análise das funções da sociedade civil como uma tendência para a determinação do apare- cimento na América Latina. Finalmente, analisamos os desafios da sociedade civil. Palavras-chave: Comunidade, Estado, forma de governo, mercado, sociedade civil

libre asociación de los ciudadanos para debatir, la que tiene que ir acompañada de la libertad de expresión. Según Fossaert, la sociedad civil es "una entidad que configura su ser en oposición con el Estado y en donde nuevas organizaciones sociales se forman separadamente de éste y en ocasiones hasta lo enfrentan".

La sociedad civil se define como "la esfera de interacción social situada entre la economía y el Estado, compuesta sobretodo por la esfera íntima (especialmente la familia), la esfera de las asociaciones (en particular las asociaciones voluntarias), los movimientos sociales y las formas de comunicación pública", de acuerdo a Cohen y Arato ${ }^{1}$. La sociedad civil se conceptualiza también como una esfera directamente conectada al ámbito del Estado por medio de una red de autoridades administrativas autogobernadas y otros cuerpos cooperativos, pero de carácter anti-político.

Por lo tanto, de acuerdo a Torres-Rivas ${ }^{2}$, el concepto de la sociedad civil se asocia a una versión ideológica y política conservadora que pretende reducir el papel del Estado y al sector público reforzando la acción privada y que privilegia la vida asociativa. La sociedad civil es aquella esfera históricamente constituida de derechos individuales, libertades y asociaciones voluntarias, cuya autonomía y competición mutua en la persecución de intereses e intenciones privados quedan garantizadas por una institución pública, llamada Estado” de acuerdo a López Calera ${ }^{3}$.

La sociedad civil "Es un espacio donde las clases y las fracciones de clase, expresan sus intereses a través de diferentes instituciones, organismos e individuos, los cuales se confrontan y resuelven en el ámbito de la superestructura en

${ }^{1}$ COHEN, Jean, ARATO, Andrew. Civil society and political theory. Cambridge, Massachusetts: MIT Press, 1997.

2 TORRES-RIVAS, 2001. UNESCO. Nuestra diversidad creativa. Informe de la Comisión Mundial de Cultura y Desarrolo. Mexico, 1997.

${ }^{3}$ LÓPEZ CALERA, N. Yo, el Estado. Madrid: Ed. Trotta, 1992. 
una formación social determinada"4. . La sociedad civil como espacio contiene a las instituciones, organismos e individuos que representan los intereses de las clases sociales.

La sociedad civil compendia un grupo heterogéneo de individuos y colectividades cuya característica común es que no forman parte del Estado, y que son capaces de movilizarse como actores políticos para la defensa de sus intereses y para la promoción de cambios económicos, sociales, políticos, culturales, etc. Así la sociedad civil comprende las "instituciones, entidades, personalidades que representan y manifiestan los intereses de las clases sociales, pero sobretodo de las clases dominadas "mediante la actuación de instituciones e individuos que no pueden representar esos intereses en el Estado (espacio) o sociedad política".

Martínez Nogueira ${ }^{5}$ sostiene que la sociedad civil es "un ámbito inserto entre el Estado y el individuo en el que se despliega la sociabilidad, se protegen los derechos y se ejerce el control social sobre la discrecionalidad de un Estado al que en este campo sólo le corresponde el respeto a la libertad de asociación y a las iniciativas sociales"

El concepto prevaleciente de sociedad civil es que es un sistema de asociaciones civiles autorreguladas, descentralizadas y voluntarias, basadas en una vida moral y organizadas en forma autónoma del Estado. De hecho, el elemento central del concepto de sociedad civil es la práctica que tiene como base una actividad asociacionista y que tiene lugar fuera de la esfera de influencia de las funciones del Estado y fuera de las estructuras formales de las organizaciones e instituciones oficialistas. El concepto de sociedad civil amplía la esfera pública superando la dicotomía de lo estatal y privado. La sociedad civil está formada por un conjunto de organizaciones y asociaciones que se desarrollan y actúan en la esfera pública pero independiente y autónoma del Estado conforme a determinados principios sociales y regulaciones que lo separan del poder político y del Estado.

La sociedad civil está formada por agrupaciones que tienen intereses públicos, privados o ambos, mientras que los partidos políticos son de interés público. Las organizaciones que integran la sociedad civil y los partidos políticos están

\footnotetext{
${ }^{4}$ URQUIZA, Waldemar, ULLOA, Félix. La sociedad civil salvadoreña frente a los actuales problemas nacionales. Diálogo - debate. 2001.

${ }^{5}$ MARTINEZ NOGUERA, Roberto. Estado, sociedad civil y gestión pública. Parte I y II. Magazine, n. 25. Instituto Internacional de Gobernabilidad, 18 de diciembre del 2001.
} 
compuestos por ciudadanos cuya única diferencia es de naturaleza jurídica. En este sentido el concepto de sociedad civil se expande hasta comprender los conceptos de ciudadanía y derechos humanos. Salamon y Anheier ${ }^{6}$, ven a la sociedad civil como "la plétora de organizaciones privadas, sin fines de lucro y no gubernamentales que han emergido en las décadas recientes en virtualmente cada esquina del mundo para proveer vehículos a través de los cuales los ciudadanos pueden ejercer iniciativa individual en la persecución privada de los propósitos públicos".

Para Gramsci, la sociedad civil está compuesta por organizaciones privadas que constituyen prototipos de las relaciones que establecen entre los seres humanos. El concepto sociedad civil predominante nada tuvo que ver con la idea de Gramsci, pues ése sí se conectaba con los partidos y las vías al poder a fin de construir nuevas hegemonías en la sociedad, para transformarse ella y a las instituciones. Es decir, no es posible transformar una sociedad y el Estado sin una idea o proyecto global sobre la economía, el Estado, las leyes; y la sociedad civil requiere instrumentos propios para organizarse y organizar a todos los estratos de la sociedad.

El concepto sociedad civil, de acuerdo a Razcón ${ }^{7}$, como medida para contener los sectarismos ideológicos, se volvió "compañero del neoliberalismo en la medida en que se convirtió en la conciencia crítica del nuevo modelo económico, mientras el rechazo a la lucha por el poder se tradujo en fundaciones, organismos no gubernamentales y civiles, basados fundamentalmente en la filantropía.

La sociedad civil constituye una red de individuos privados unidos por sus relaciones legales (contrato social) y se concibe su esfera como una comunidad de valores compartidos basada en las múltiples asociaciones de los ciudadanos ${ }^{8}$. La sociedad civil es una red asociativa que comprende todos los intereses sociales y facilita la participación de los ciudadanos que forman parte de un sistema político. La sociedad civil está integrada por una red compleja de asociaciones voluntarias de ciudadanos con una participación activa para mantener los intereses comunes en forma independiente y autónoma del Estado. Así, la sociedad civil es vista más en términos de relaciones que como espacio.

\footnotetext{
${ }^{6}$ SALAMON, Lester, ANHEIER, Helmut. The civil society sector. Society. 34, 2.

${ }^{7}$ RAZCÓN, Marco. La critica de la critica al neoliberalismo. La Jornada. México, D. F., 6 de agosto del 2002.
}

${ }^{8}$ HONNETH, Axel. Concepciones de la sociedad civil. Este País. Número 102, septiembre, 1999. 
La sociedad civil conceptualizada como el espacio donde se expresan las mayorías por sí mismas o a través de sus instituciones, es considerarla como una instancia de resolución de conflictos económicos, políticos y sociales, o que bien los trasciende en forma de demandas al espacio estatal. La sociedad civil está formada por el conjunto de intereses de los sujetos que se relacionan entre sí a través de las instituciones y las organizaciones creadas para tal fin. El concepto de sociedad civil como sujeto, asume "roles y representaciones que corresponden a sujetos específicos" "tales como los partidos políticos, las organizaciones no gubernamentales, etc., toma ventaja de sus posiciones dentro del espacio, para la defensa de sus propios intereses. Sin embargo, la sociedad civil no es un sujeto en sí misma, sino la esfera en la actúan y realizan sus actividades las instituciones y entidades que la forman.

Así, el lugar en que se efectúan mediaciones y contestaciones entre la sociedad y el Estado y con las macro instituciones del poder económico y cultural, es lo que Rocco ${ }^{10}$ denomina sociedad civil. Estos sitios de mediación son los lugares de la vida diaria, donde los individuos y los grupos entran en contacto mediante normas, fronteras, tradiciones, y redes que definen las relaciones institucionales, etc.

Existen muchas lógicas en la moderna sociedad que compiten y son inconsistentes, pero la presencia y extensión de los conflictos permanece para ser evaluados empíricamente. El buen desempeño económico, político y social se fundamenta en la confianza que es un catalizador de conflictos potenciales y en las redes de cooperación que se construyen con la asociatividad horizontal.

\section{La sociedad civil como forma de gobernancia}

La sociedad civil es la forma de autoorganización social más natural y orgánica de todas las formas de organización. La sociedad civil se basa en normas de reciprocidad, confianza e intercambio mutuo que tienen lugar dentro de ciertos espacios institucionales y que median la relación entre los hogares y las institu-

\footnotetext{
${ }^{9}$ URQUIZA, Waldemar, ULLOA, Félix. Op. cit.

${ }^{10}$ ROCCO, Raymond. The formation of latino citizenship in Southeast los Angeles. Citizenship Studies. Vol. 3, n. 2, 1999.
} 
ciones que controlan y tienen el poder sobre los recursos económicos, políticos y culturales. A mayor complejidad de las relaciones de poder entre los diferentes agentes y actores económicos y políticos, la sociedad civil tiende a ser más democrática.

El término gobernancia que hace referencia a la conducción de las interrelaciones de la sociedad civil con el Estado y el mercado, la coordinación de actores, grupos sociales e instituciones, proviene del francés goubernancia usado en los siglos XVI y XVII y de la noción traducida del Inglés governance utilizado para delimitar el ámbito de intervención socioeconómica de las empresas. El término de Governance originalmente significó la forma en que el poder o la autoridad política, administrativa o social se ejerce en el manejo de los recursos o asuntos que interesan al desarrollo. Governance significa el marco de comportamiento de los individuos, las organizaciones y las empresas. Governance es la determinación de los usos amplios en los cuales los recursos organizacionales son expuestos y la resolución de conflictos entre todos los participantes en las organizaciones.

Governance es una forma de gestionar la estructuración del régimen para alcanzar una mayor legitimidad en las acciones políticas del gobierno y del Estado, así como de los diferentes actores de la sociedad civil. Un régimen es un "conjunto de reglas fundamentales sobre la organización del espacio público", que comprende tanto al Estado como a la sociedad civil y divide lo público y lo privado ${ }^{11}$. El governance se entiende, según Prats ${ }^{12}$ como las "instituciones y reglas que fijan los límites y los incentivos para la constitución y funcionamiento de redes interdependientes de actores (gubernamentales, del sector privado y de la sociedad civil).

Para Prats ${ }^{13}$ la governance como metapolítica que concierne "a la estructura institucional de la acción política tanto del gobierno como de los actores de la sociedad civil", tienen una dimensión estructural y otra dimensión dinámica o de proceso. La governance, no se refiere solo a las organizaciones gubernamentales

\footnotetext{
${ }^{11}$ PRATS, Joan. Governabilidad democrática para el desarrolo humano. Marco conceptual y analitico. Instituciones y Desarrolo. Barcelona, España. N. 10, octubre 2001. http://www.iigov.org/ revista/re10/re10_04.htm.

${ }^{12}$ Idem.

${ }^{13}$ Idem.
} 
porque enmarcan y entrelazan una serie interdependiente de actores que comprende los gobiernos, los actores de la sociedad civil y el sector privado, tanto en el ámbito local, nacional e internacional ${ }^{14}$.

Deckker y Van den Broek ${ }^{15}$, basándose en un análisis propio acerca los principales argumentos del debate sobre la posición de la sociedad civil en Los Países Bajos, ofrecen una representación gráfica que relaciona la distancia de varias instituciones de los Estados modernos de bienestar en los cuatro modelos de orden social mencionados.

El desarrollo social se sustenta en las interrelaciones entre el Estado, mercado y sociedad civil. En una sociedad más desarrollada se fortalecen el Estado, el marcado y la sociedad civil, como instrumentos del desarrollo mismo. En este tipo de desarrollo, las organizaciones de la sociedad civil representan un papel central en la promoción y facilitación de la participación social en la definición de las políticas de desarrollo, la cual es delimitada como un problema de gobernabilidad en la que se determinan las reglas de juego de los agentes para la formulación de las políticas públicas.

La transnacionalización del Estado presupone la transnacionalización del capital y de la sociedad civil no sin provocar conflictos en el centramiento del Estado nación o en la dualidad nacional- global. Según Honneth ${ }^{16}$, el concepto de sociedad civil concepto "sitúa el núcleo civil de una sociedad a igual distancia de la esfera económica y política de la sociedad". La sociedad civil al ser parte de la superestructura facilita la operabilidad de las relaciones con otras instancias al mismo nivel, como el Estado-aparato y que difieren de las contradicciones que se generan entre las fuerzas productivas y las relaciones de producción.

Las nuevas formas de organización y relación entre el Estado y la sociedad civil se encuentran más bien sujetas a una multiplicidad de dinámicas comple-

\footnotetext{
${ }^{14}$ PNUD. Governance for sustainable human development. Nueva York: PNUD, MDGD-BPP, UNDP Policy Document, 1997, in: PRATS, Joan. Op. cit.

${ }^{15}$ DECKKER, Paul, BROEK, Andries van de. Civil society in comporrative perspective: involvement in voluntary associations in North America and Western Europe. Voluntas: International journal of Voluntary and Nonprofit Organizations. V. 9, n. 1, 1998.
}

${ }^{16}$ HONNETH, Axel. Op. cit. 
jas regidas por los intereses y fines del mercado. Las instituciones y las normas constituyen la base del funcionamiento interrelacional que determina el grado de racionalidad instrumental entre los diferentes actores del Estado (gobiernos, burócratas, políticos, etc.) el mercado (propietarios privados) y la sociedad civil.

La sociología política describe la complejidad y la fragilidad de la inserción de la sociedad civil en la esfera pública y endereza las criticas hacia el modelo de desarrollo neoliberal impuesto por el Estado. Estado y mercado existen para representar los intereses de lo público y lo privado de una misma realidad social. El lugar en el que la sociedad entra en relación con el Estado constituye la sociedad civil, la cual no actúa como un sujeto sino como un espacio o esfera donde expresan y se manifiestan sus instituciones y entidades que la forman.

Por lo tanto la sociedad civil no debe ser considerada como un sujeto, sino como una esfera o espacio donde se expresan determinados intereses. La capacidad de demanda de algunos grupos de interés sobre el Estado limita el pretendido universalismo del bien público, para adoptar estrategias basadas en tendencias focalistas, contingentes, descentralizadas y de terciarización del sector privado y la sociedad civil. El mismo carácter anti-político de la sociedad civil fragmenta los intereses y limita sus aportaciones a la construcción de las instituciones.

El modelo de desarrollo neoliberal con su estrategia que favorece a los capitalistas, estimula la formación y funcionamiento de una sociedad civil motivada en los valores democráticos que se contraponga a las decisiones autoritarias del Estado, reduzca sus funciones para dar más campo de acción al libre mercado. Las funciones públicas contingentes toma en consideración aquellas actividades que pueden ser subcontratadas (outsourcing) o privatizadas y que desestructura las principales funciones del Estado moderno a las que Dror ${ }^{17}$ denominó como "las funciones de orden superior" del Estado.

El nuevo modelo de crecimiento económico centrado en el empresario privado que actúa en el mercado, ha desacreditado al Estado, desvalorizado la esfera pública y se apoya en la acción dentro de determinado límites de la sociedad civil. Así, propone una relación directa de fortalecimiento mutuo entre la sociedad civil y la democracia.

La sociedad civil se caracteriza con relación al Estado, en que este último constituye el espacio que sirve para la expresión de los intereses de sectores

\footnotetext{
${ }^{17}$ DROR, Yehezel. Fortalecimento de la capacidad de los gobiernos en material de formulación de politicas. Documento presentado a la 12 Reunión de expertos del Programa de las Naciones Unidas en material de Administratión y Finanzas Públicas. Nueva York, 31 de Julio a 11 de agosto de 1995: 222.
} 
minoritarios de la sociedad y cuyas instituciones también están en función de los intereses del Estado. Las organizaciones de la sociedad civil proyectan y despliegan la capacidad de la acción del Estado. La participación política de los actores y movimientos sociales tradicionales y nuevos en el actual proyecto democrático, que enfatiza la redefinición del papel del Estado y la construcción de una sociedad civil, es muy limitada si se instrumenta bajo esquemas de racionalidad económica.

Para evitar la organización espontánea de la sociedad civil, los gobiernos privilegian programas de asistencia social donde no se haga mucho énfasis en el desarrollo comunitario y donde se encubra el apoyo gubernamental como despojado de su carácter de proselitismo político.

\section{Mercado}

Para los neoliberales, el mercado es el mejor asignador de los recursos y el Estado debe jugar un papel subsidiario, mientras que la sociedad civil se conforma por un conjunto de organizaciones y agrupaciones de individuos que en forma voluntaria logran objetivos conjuntos. Organizaciones privadas y del mercado son persuadidas por la lógica de le eficiencia económica y las organizaciones públicas y no del mercado por la lógica de la apropiabilidad. La responsabilidad a lógicas diferentes resulta en heterogeneidad de adopción de nuevas prácticas y en la forma en que adoptan. La promesa hecha por la globalización corporativa de que los mercados mantendrían el equilibrio ha resultado en un desequilibrio en beneficio de los países más desarrollados.

La lógica de los mercados sustituye las relaciones basadas en la reciprocidad de las obligaciones entre las personas por las relaciones centradas en transacciones monetarias, lo cual debilita la solidaridad entre los individuos y los pueblos y las identidades comunitarias. Así, un elevado desarrollo económico puede coexistir con un debilitamiento de las relaciones de confianza y cooperación cívica ${ }^{18}$. Pero cuando el mercado empieza a mostrar sus grandes fallas, la responsabilidad para corregirlas se transfiere al papel diferenciado de la sociedad civil. Las privatizaciones de las empresas propiedad del Estado no están dando

${ }^{18}$ GROOTAERT, Christiaan. Social capital: the missing link? Social Capital Iniciative. Paper 3, World Bank, April, 1998. 
los beneficios y ventajas esperadas a la ciudadanía y a la sociedad civil en términos de calidad, precios, etc., y si han quedado más expuestas a los impactos de los efectos de las crisis financieras.

Con la crisis ideológica del neoliberalismo que tiene implicaciones con la crisis económica y social que debilita los sistemas políticos, se cuestionan los principios del libre mercado, se promueven las acciones de la sociedad civil y se reivindican las funciones complementarias del Estado. Investigaciones sobre la cultura política concluyen que la crisis política tiene poca relación con la crisis de confianza en las instituciones democráticas cuyo nivel de aceptación sigue siendo elevado.

Algunas características de comunidad, mercado, Estado y sociedad civil como tipos ideales de orden social

\begin{tabular}{|c|c|c|c|c|}
\hline Criterios & Comunidad & Mercado & Estado & Sociedad Civil \\
\hline Principios guía & Solidaridad & Competencia & Jerarquía & Voluntariedad \\
\hline $\begin{array}{l}\text { Actores } \\
\text { colectivos } \\
\text { dominantes. }\end{array}$ & $\begin{array}{l}\text { Familias, } \\
\text { vecindades. }\end{array}$ & $\begin{array}{l}\text { Negocios, } \\
\text { partidos políticos. }\end{array}$ & $\begin{array}{l}\text { Agencias } \\
\text { burocráticas. }\end{array}$ & Asociaciones. \\
\hline $\begin{array}{l}\text { Prerrequisito para } \\
\text { la participación. }\end{array}$ & Adscripción. & Poder de compra. & Autorización legal. & Compromiso. \\
\hline $\begin{array}{l}\text { Regla de decisión } \\
\text { principal. }\end{array}$ & Consenso. & $\begin{array}{l}\text { Oferta y } \\
\text { demanda. }\end{array}$ & $\begin{array}{l}\text { Adjudicación } \\
\text { autoritaria. }\end{array}$ & Debate. \\
\hline $\begin{array}{l}\text { Medio de } \\
\text { intercambio. }\end{array}$ & Estima. & Dinero, votos. & Coerción. & Argumentos. \\
\hline $\begin{array}{l}\text { Tipo de bienes } \\
\text { generados. }\end{array}$ & $\begin{array}{l}\text { Bienes } \\
\text { solidarios. }\end{array}$ & Bienes privados. & Bienes colectivos. & Bienes mixtos \\
\hline $\begin{array}{l}\text { Externalidades } \\
\text { positivas. }\end{array}$ & $\begin{array}{l}\text { Afección } \\
\text { mutua, } \\
\text { identidad } \\
\text { colectiva. }\end{array}$ & $\begin{array}{l}\text { Prosperidad, } \\
\text { responsabilidad. }\end{array}$ & $\begin{array}{l}\text { Seguridad, } \\
\text { justicia. }\end{array}$ & $\begin{array}{l}\text { Capital social, } \\
\text { Discurso } \\
\text { público }\end{array}$ \\
\hline
\end{tabular}




\section{Estado}

La forma de gobernabilidad centrada en el Estado nación se encuentra en una relación de transformación con los procesos de globalización económica del sistema capitalista. El Estado intervencionista usa el poder para colonizar la sociedad y el Estado neoliberal subyuga a la sociedad al libre juego del mercado, limitando con ello las posibilidades de la sociedad civil para establecer una gobernabilidad democrática. El modelo económico neoliberal limita la participación del Estado en la solución de problemas sociales, los cuales transfiere a la sociedad civil. El Estado subsidiario difícilmente puede alcanzar la estabilidad democrática aún contando con el apoyo de una sociedad civil fuerte, aunque esta si puede influir en la corrección del rumbo del Estado a través de movimientos sociales y revolucionarios.

Hacia dentro del Estado nación se presenta la lucha de intereses para lograr el aseguramiento del acceso a los recursos mediante la conquista del poder. Surgió así la gran estructura de la financiación con nuevos centros de poder, que sí establecieron vínculos concretos con los grupos de acceso al poder político del Estado.

Una sociedad civil vigorosa fortalece al gobierno democrático. En este sentido la gobernabilidad de un sistema social mantiene su estabilidad política. Es democrática porque presupone el gobierno democrático, hace del control social por la sociedad civil una forma principal de accountability política, y requiere transparencia de las agencias públicas. Es social-demócrata porque afirma el papel del Estado de garantizar la protección eficaz de los derechos sociales.

Desde una visión Estado-céntrica en donde los gobiernos tienen un papel predominante, la gobernabilidad es provista por una sociedad influida por redes organizacionales de grupos de interés como los iron triangles o triángulos de hierro y los issue networks o redes temáticas debilitan el papel de la gobernabilidad Estado céntrica y contribuyen a centrar la gobernabilidad en la sociedad civil misma, lo cual puede predeterminar la agenda política de los gobiernos. Es por lo tanto un problema de gobernabilidad más que de administración pública que requiere la redefinición de las funciones del Estado y de la sociedad civil.

El Consenso de Washington orienta la agenda y los desafíos de las instituciones de la sociedad civil a limitar las acciones del Estado. La implantación 
se realiza a través de las denominadas reformas administrativas orientadas a la modernización de las estructuras del aparato burocrático, la más reciente de las cuales se ha denominado la revolución gerencial que intenta redefinir el sistema burocrático sin alcanzar los beneficios esperados. El involucramiento de la sociedad civil en la reforma del Estado la orienta hacia una dimensión de reforma societal. El involucramiento societal hace referencia a las implicaciones de normas, costumbres, tradiciones, normas morales y religiosas, etc., que difieren entre los diferentes grupos de los Estados nacionales y operan como apoyos sociales para dar credibilidad a los contratos. Los actores políticos y sociales deben compartir esfuerzos administrativos para alcanzar el desarrollo compartido

La reforma del Estado incorpora elementos institucionales que promueven la coordinación de las instituciones del Estado y la sociedad civil, la eficiencia adaptativa privada y pública, y una mejor formulación e implementación de las políticas públicas. Esta eficiencia adaptativa requiere de estructuras organizacionales flexibles, normas y procedimientos simplificados y una racionalización de los recursos. Los procesos de la gestión pública requieren de un rediseño para la creación de nuevas capacidades de las instituciones políticas orientadas a promover la participación y acción de la sociedad civil en los asuntos públicos locales mediante la formación de un capital social.

El capital social fortalece las relaciones y capacidades de la sociedad civil. Para Putnam ${ }^{19}$ el capital social es un bien público basado en los aspectos de la organización social tales como la confianza, las redes y reglas que superan los dilemas de la acción colectiva para alcanzar la eficiencia social. Para Putnam², el capital social es la relación de confianza que existe entre los actores sociales, su comportamiento cívico y nivel de asociatividad como elementos viables para la acción colectiva y desarrollo de capacidades cooperativas de una comunidad.

La gestión pública del Estado transforma sus estructuras, comportamientos y procesos burocráticos para ser sustituidas por arreglos institucionales más flexibles que facilitan la participación más directa de la comunidad y de la sociedad civil en los asuntos públicos mediante la promoción de comportamientos solidarios,

\footnotetext{
${ }^{19}$ PUTNAM, Robert. Making democracy work: civic traditions in modern Italy. Princeton: Princeton University Press, 1993.

${ }^{20}$ PUTNAM, Robert. Para hacer que la democracia funciones. Caracas: Editorial Galac, Venezuela, 1994.
} 
procesos deliberativos democráticos y mecanismos de transparencia y rendición de cuentas. La nueva gestión pública es un proceso de reingeniería y rediseño de las relaciones entre los actores involucrados en la esfera estatal para la creación de valor público mediante el fortalecimiento de las instituciones a partir del aumento del capital social y el aprendizaje organizacional que promueven espacios de confianza entre el sector público, la ciudadanía y la sociedad civil.

El Estado se transforma mediante procesos de democratización y por la forma en que la sociedad civil se organiza para garantizar la fundamentación política. Los procesos de democratización política se relacionan directamente con las estructuras del tejido social que da sustento a la sociedad civil que facilita la participación en función de decisiones de mayorías políticas que eliminan, en forma parcial las manifestaciones autoritarias. La tendencia hacia una democracia sin ciudadanos como la determinante de las democracias institucionalizadas en una estructura en la cual se afirman en la confianza del sistema o se niegan en la pasividad de la participación política.

Es a partir de la dimensión territorial como la reforma del Estado de concentra en los gobiernos locales.y regionales, por ser los espacios donde se dan los máximos contactos entre la sociedad civil y el Estado y en donde por lo tanto, existen las mejores posibilidades para territorializar adaptando y flexibilizando las políticas y estrategias de desarrollo.

El respeto al derecho internacional reconocido por todos los Estados ayuda a sostener el funcionamiento de la sociedad civil. Denota una representación conceptual y teórica de la coordinación de sistemas sociales y del rol del Estado en este proceso ${ }^{21}$.

\section{comunidad}

Fronteras de los espacios de lo público y lo estatal en forma no siempre precisa entre lo privado de los individuos, la acción colectiva de las organizaciones sociales y comunidades y el ejercicio de la política. La República se concibe como una forma de gobierno basada en la libertad política de una comunidad de ciudadanos que viven el gobierno de las leyes.

${ }^{21}$ PIERRE, J. Understanding governance, in: PIERRE, J. Debating governance: authority, steering and democracy. Oxford: Oxford University Press, 2000. 
En La Política de Aristóteles se hace referencia al término koinonía politiké que literalmente significa comunidad política que se traduce al Latín como societas civilis con se denominaba a la pólis griega. La pólis, de acuerdo a Urquiza y Ulloa ${ }^{22}$ era "una forma de comunidad diferente a la familia y superior a ella, que consistía en la organización de una convivencia que cobraba las características de la autosuficiencia, de la independencia y del interés social, aspectos que a partir de la modernidad pretenderán ser las propiedades del Estado". Es necesario analizar otra distinción que Aristóteles hace en su Política sobre lo que significa la koinonía o vida comunitaria. Pues una cosa es el uso en común promovido por la ley y el castigo y otro la acción común inspirada en la filía, que es la virtud de la polis. De la lectura de algunos pasajes de la Política y en armonía con lo que inspira a la Ética a Nicómaco puede "destilarse" una distinción conceptual que yo expresaría distinguiendo entre "colectividad" y "comunidad" en el lenguaje moderno.

De acuerdo con Tomassini ${ }^{23}$, "la idea de la sociedad civil encarna de esta manera un ideal ético del orden social, no ideal, que si no supera, por lo menos armoniza las conflictivas demandas entre los intereses individuales y colectivos". Este proceso de colectivización puede ser si las sospechas iniciales son eliminadas No obstante, se considera que si las instituciones de la sociedad civil valoran la individualidad mediante la defensa de los derechos individuales y los valores de la colectividad, tales como la confianza, entonces la sociedad civil puede ser más democrática.

En el modelo republicano de democracia el centramiento es en la construcción de las identidades individuales y colectivas a través del diálogo en un espacio público para la participación de los ciudadanos activos en el cual la política crea preferencias en la búsqueda del bien común considerados como sujetos responsables, libres e iguales en una comunidad. En la sociedad civil, los ciudadanos tienen las posibilidades de ejercitar su libertad y en los términos de igualdad de oportunidades. La ciudadanía es considerada como una esfera abierta de participación parea la formación de una voluntad política.

\footnotetext{
${ }^{22}$ URQUIZA, Waldemar, ULLOA, Félix. Op. cit.

${ }^{23}$ TOMASSINI, L. La revalorización de la sociedad civil, in: La reforma del Estado y las políticas públicas. Centro de Análisis de Políticas Públicas. Universidad de Chile, Santiago, 1994.
} 
La conformidad cultural es una condición y un medio para la obtención de la ciudadanía de quienes participan en las prácticas sociales y sus correspondientes valores, adaptándose a los patrones culturales dominantes que movilizan su conexión con una comunidad imaginada, cuyo ideal es la comunidad cultural, lingüística, étnica, religiosa.

Los integracionistas demandan que todos los miembros de los grupos asentados en un territorio formen una comunidad mediante la internalización y conformidad de valores, sin dejar de reconocer el derecho de las minorías para expresar su propia cultura en los dominios intercambiables de lo público y privado. Desde el punto de vista integrativo se defiende la uniformidad e integridad de la sociedad y del Estado nación para promover causas comunes y sobre la base de una comunidad de valores fundamentales y estándares de los grupos que forman la sociedad permite la expresión de la pluralidad de la sociedad y cuya meta se orienta a la abolición de las diferencias culturales.

El cambio a las instituciones del Estado no ha sido exitoso en la creación de poder de las comunidades y en hacer más efectivas a las autoridades locales y a las agencias de la sociedad civil en la articulación y en la acción de demandas sociales. Las transferencias de conocimientos y experiencias entre las organizaciones de la sociedad civil son además instrumentales en apoyos a las comunidades para neutralizar y combatir políticas negativas a la promoción del desarrollo social sustentable de los gobiernos, de grandes corporaciones transnacionales y multinacionales y de los grandes capitales financieros. La capacidad de organización comunitaria entre los diferentes sectores de la población, sobretodo los más desprotegidos que padecen carencias, o en situaciones extremas de desastres, ha motivado la emergencia espontánea del apoyo solidario de diferentes grupos de la sociedad civil, desafiando la lentitud en las respuestas de las instituciones gubernamentales.

Debido a que las respuestas a los diferentes problemas comunitarios surgen de las propias organizaciones de la comunidad, su conocimiento y su compromiso son más profundos que los diseñados por las instituciones públicas. La promoción del desarrollo comunitario tiene fines pragmáticos al intentar hacer algo por los miembros de la comunidad, y fines democráticos al buscar la autoafirmación como comunidad. No obstante, la devolución del poder social y político a las comunidades, junto con la implementación de una política económica inclusiva por el Estado, es crucial para la promoción de un desarrollo participativo y justo. 


\section{Sociedadcivil}

La sociedad civil se encuentra según Wolfe ${ }^{24}$ en "familias, comunidades, redes de amistad, conexiones solidarias en los lugares de trabajo, voluntarismo, grupos espontáneos y movimientos". Las organizaciones voluntarias y el voluntarismo parecen ser los elementos centrales de la sociedad civil de acuerdo con Deckker y Van den Broque ${ }^{25}$. Estos autores proponen la "voluntariedad como el principio guía de la sociedad civil y las asociaciones como sus actores colectivos dominantes. Las redes de actores individuales y colectivos "representan un nexo sobresaliente en la relación entre las personas y los sistemas funcionales" ${ }^{26}$.

La sociedad es uno de los actores sociales que promueve el desarrollo en sus diferentes formas. La sociedad civil se organiza en forma autónoma al Estado, pero no como un sujeto sino un espacio o esfera donde se expresan intereses. Sin embargo, tanto la sociedad civil como el Estado son actores sociales del desarrollo. Debido a los procesos de globalización que traspasan las fronteras de las naciones mediante la emergencia de una sociedad civil global, el Estado transfiere sus responsabilidades hacia las nuevas estructuras sociales y las organizaciones no gubernamentales, de tal forma que los poderes de las naciones se trasladan a un espacio global despolitizado, es decir, que las naciones ceden a la sociedad civil global.

Esta transferencia de funciones del Estado a la sociedad civil tiene lugar después de que lamentablemente el Estado ha descuidado la infraestructura y los servicios públicos. La sociedad civil se expresa en la intensionalidad ética y la responsabilidad social de sus resultados a través de la acción de sus organizaciones. La administración de las organizaciones de la sociedad civil ha sido influida por la ética calvinista del trabajo.

La emergencia de las organizaciones de la sociedad civil tiende a equilibrar las relaciones entre el Estado y el mercado, lo cual contribuye a lograr mejores niveles de crecimiento económico, desarrollo social y libertad política de los

\footnotetext{
${ }^{24}$ WOLFE, A. Whose keeper. Berkeley, California: University of California Press, 1989.

${ }^{25}$ DECKKER, Paul, BROEK, Andries van den. Op. cit.

${ }^{26}$ LECHNER, Norbert. Desafíos en el desarrollo humano: individualización y capital social. Instituiciones y desarrollo. N. 7, noviembre 2000.
} 
pueblos y reducir las brechas generadas por las desigualdades. El equilibrio entre el poder del Estado, el dinero del mercado y las formas de creencias de la sociedad civil son importantes para que funcione el mercado, es decir, se requiere el balance entre el mercado, el sector privado y el gobierno o el Estado.

El sistema político constituido por las instituciones públicas y los partidos políticos es autónomo en su actividad política en la que participa la ciudadanía, y puede ser vehículo de intermediación entre el Estado y la Sociedad civil. Un sistema político liberal fuerte que se oriente hacia la democracia, no necesariamente requiere de una sociedad civil también fuerte pero si apoyada en valores liberales que fortalecen las estructuras políticas, de tal forma que tienda a equilibrar las diferencias económicas y sociales que crea el mercado. El sistema de partidos políticos entra en crisis y son rebasados por una sociedad civil mas demandante y participativa, y por los medios de comunicación que se asumen como actores políticos para servir de intermediarios en las demandas de la sociedad.

Sin embargo, tanto la sociedad civil como los partidos políticos tienen funciones y actividades que son complementarias y por lo tanto no tienen intereses necesariamente antagónicos. Los partidos políticos buscan el acceso al poder político, realizan la gestión social y proponen proyectos económicos, punto en el que hay mucha coincidencia con las funciones de las organizaciones de la sociedad civil, aunque los partidos políticos representan los intereses generales y pueden beneficiarse con las acciones de las organizaciones civiles que persiguen intereses más específicos. Los componentes de la sociedad civil pueden contribuir a potenciar la ideología y los programas de acción de los partidos políticos, para que representen intereses heterogéneos.

Una sociedad civil vigorosa fortalece al gobierno democrático. Instituciones democráticas saludables y economías fluorescentes crecen de una raíz común, de una vigorosa sociedad civil, a pesar de que las mismas instituciones democráticas no pueden garantizar los resultados de la aplicación de las políticas públicas. Es la sociedad civil la que instituye la función pública mediante la creación de un arreglo constitucional. La dinámica de las instituciones existentes y la sociedad civil son el fundamento que determinan el modo de gobierno y su nivel de gobernabilidad democrática.

"La calidad del ejercicio democrático del poder depende de la acción conjunta de dos elementos: Por una parte, de la naturaleza de las instituciones del Estado, la responsabilidad y transparencia de los funcionarios estatales, y por 
la otra, de la naturaleza de la sociedad civil y su capacidad para ejercer control sobre el aparato del Estado"27. A su vez, el desarrollo democrático de las sociedades impulsa la sociedad civil. Así entonces, la sociedad civil es vista como un receptáculo inerte de todo lo que haga el gobierno.

La política estratégica está constituida más por la sociedad civil que establece la reforma y legitima a las instituciones, más que por las instituciones por sí solas. La satisfacción con la forma de gobierno en sí misma no significa legitimidad, sino que también es importante considerar las actitudes hacia las otras alternativas políticas extremas manifiestas en esos intereses heterogéneos. Su legitimidad democrática no se establece solamente porque alegan que son parte de la sociedad civil. Si no existe legitimidad de las instituciones que implica la manifestación de confianza y aprobación del mandato conferido por la ciudadanía, tampoco existe gobernabilidad.

La actividad económica que define la dimensión social reclama un espacio fuera de las estructuras políticas de la sociedad y por tanto sin identidad política, pero además fuera del espacio del Estado, integrando lo que se ha denominado sociedad civil. La participación de organizaciones sociales y comunitarias en la producción, prestación y control de bienes y servicios públicos, fortalece a la sociedad civil, modifica la relación público privado y elimina el monopolio que tradicionalmente ha tenido el Estado. Un prerrequisito de participación en la sociedad civil es la entrega: la voluntad para sostenerse a sí mismo en un curso de acción y tomar responsabilidades.

La sociedad civil se identifica con una pluralidad de las asociaciones voluntarias y no con el mercado y los agentes económicos particulares con fines especulativos, como se pretende. En las mismas formas de organización social que están estrechamente vinculadas con la política, ocurre la estructuración de la sociedad civil que fomenta relaciones asociacionales animadas por ciertos valores ideales democráticos para dar sustento a la participación ciudadana. Así, en las instituciones de la sociedad civil se encuentran formas de organización de las más variadas, desde las fundamentales con intereses económicos y sociales hasta aquéllas formas organizativas que tienen por objeto de trabajo el conocimiento, la información, la ideología, etc.

Es cuestionable considerar que el mercado es parte del ámbito de la sociedad

${ }^{27}$ TORRES-RIVAS. Op. cit. 
civil, tomando en cuenta que ésta no constituye el Estado. Las semillas de las virtudes cívicas no se encuentran en las instituciones económicas y políticas, sino en las asociaciones voluntarias de la sociedad civil, empezando con la familia.

En la democracia social, el ethos de la sociedad exige la igualdad de los miembros de la sociedad civil que en posiciones y estructuras horizontales dan sustento a comunidades y asociaciones voluntarias. La creación de nuevas estructuras que democraticen los espacios para la participación ciudadana activa capaz de transmitir la agregación de los intereses individuales en forma representativa de la voluntad general.

Tanto el voluntarismo como los patrones de la sociedad civil refuerzan los movimientos de acción ciudadana. La asociación voluntaria de los individuos en la denominada sociedad civil contribuye a la formación de redes de solidaridad, al forjamiento de identidades colectivas de los pueblos y a la organización para lograr fines colectivos y superar cualquier contingencia.

Sí de los intereses privados se desarrollan mediante la asociación de los individuos en la comunidad, por lo que "en el interior de la sociedad se organizan los intereses privados del ciudadano y cuando ellos están animados por una voluntad de defensa de lo propio y de lo colectivo, de servicio público, de asociación en provecho de derechos sociales y políticos, surge la sociedad civil" de acuerdo a Torres-Rivas ${ }^{28}$, quien concluye que "La sociedad civil existe cuando la sociedad como totalidad puede estructurarse a sí misma y coordinar sus acciones a través de un conjunto de asociaciones voluntarias".

La opinión pública es la característica que diferencia la sociedad civil del Estado y que representa la voz de la sociedad civil en la esfera política. En sí misma, la opinión pública es la fuerza de la sociedad civil que es capaz de confrontar el poder establecido e impulsar cambios sociales, económicos y políticos. La sociedad política legaliza las acciones de la sociedad civil y ordena su funcionamiento con una orientación hacia la esfera pública.

La relación existente entre la sociedad civil y el sistema político se analiza mediante el concepto de capital social desde su función. El vínculo social es un recurso del capital social para el desarrollo económico, el cual se presenta en forma neutral para ser aprovechado mediante diferentes estrategias. El capital social es un recurso acumulable que crece si se hace uso o se devalúa si no es

\footnotetext{
${ }^{28}$ Idem.
} 
renovado. El capital social fortalece las relaciones y capacidades de la sociedad civil. Así, las organizaciones de la sociedad civil promocionan el desarrollo de capacidades sociales y políticas de los ciudadanos, en lo que Putnam ${ }^{29}$ ha denominado como la formación del capital social. Putnam no explica como la implicación en grupos afecta el comportamiento de los actores y como la sociedad civil afecta al gobierno.

El capital social se distribuye desigualmente en los diferentes grupos socioeconómicos que forman parte de la sociedad civil dependiendo de los niveles de educación e ingreso existentes. El capital social fortalece las relaciones y capacidades de la sociedad civil. Las relaciones de confianza entre los individuos y el compromiso cívico dependen de las oportunidades y las restricciones que ofrece el contexto histórico-social. Newton ${ }^{30}$ examina la subjetividad del capital social compuesto de valores y actitudes que afectan las formas de relación entre las personas.

El capital social tiene carácter instrumental y expresivo, fortalece la subjetividad frente a la modernización y es también una relación "puramente expresiva y gratuita" como fin en si misma y que además crece en la medida en que la modernización avanza ${ }^{31}$. Cruz" ${ }^{32}$ lo define como "un conjunto de fenómenos que implican dos situaciones: Existe una particular estructura social, y que esta es determinante para ciertos modos de actuar, tanto al nivel individual como al colectivo."

Cuando la sociedad civil está en contra del Estado se sustenta en principios de identidad comunitaria. La ciudadanía como una identidad abstracta es una construcción política que es cuestionada por la identidad social. Una sociedad civil en contra del Estado cuestiona sus funciones y roles tanto en los asuntos internos que son de su competencia como los asuntos externos que implican su inserción en lo global.

${ }^{29}$ PUTMAN, R. Op. cit., 1993.

${ }^{30}$ NEWTON, Kenneth. Social capital and democracy. In: American Behavioral Scientist. V. 40, n. 5, pp. 575-585.

${ }^{31}$ LECHNER, Norbert. Op. cit.

${ }^{32}$ CRUZ, César Nicandro. La justificación del poder en el proceso de la politicas públicas: implicaciones de la governabilidad democrática. In: Desarrolo Humano Institucional en América Latina, n. 27, 26 de febrero del 2002. 
La emergencia de la sociedad civil está conectada con el descrédito del Estado. La colaboración de la sociedad civil con el gobierno para la provisión social puede generar interrelaciones sinergéticas para la co-producción de servicios que van más allá de las relaciones de complementariedad, lo cual requiere además de nuevas bases estructurales, procedimentales y comportamentales.

\section{El carácter evolutivo de la sociedad civil}

La sociedad civil es evolutiva, pasa por procesos de transformación, hasta llegar a desarrollarse en redes formales e informales de individuos voluntarios. La facilidad de acceso que tienen los individuos a las redes formales e informales para la consecución de sus objetivos, se posibilita por lo que ofrecen los contactos con estas mismas redes, en los términos de recursos instrumentales, tales como el apoyo y el consejo relacionado con las actividades, y por los recursos emocionales como la amistad.

En las sociedades antiguas se identificaba a la sociedad con política como en el caso de la Ágora griega, por lo que se desprende que la comunidad existe antes que el Estado. Si bien la sociedad civil es privada en sus orígenes, los intereses y derechos colectivos se realizan en la vida política y pública. El concepto de civil society hace alguna referencia al concepto de societas civiles de Aristóeteles con que se denominaba a la forma de comunidad de la pólis. En el libro II cap. $2\{1261$ a\} refuta Aristóteles la tesis platónico-socrática de que el Estado o Polis deba ser lo más unitario posible. "La Pólis -dice Aristóteles- no es un unidad de la manera que algunos afirman. Y lo que algunos llaman el mayor bien común en realidad lo destruye", "No hay pues que buscar la unicidad de la sociedad en grado exagerado".

Para Aristóteles la familia es la forma social más unitaria, pero no la más autosuficiente. El Estado-ciudad es autosuficiente no siendo tan unitario, pues la autosuficiencia es preferible a la unicidad. Todo estado-ciudad que tienda a mayor unicidad tiende a dejar de ser un estado-ciudad para convertirse en una especie de alianza militar. Pues una pólis se caracteriza por una pluralidad de individuos que son diferentes. En los trabajos clásicos de Platón y Aristóteles se asegura que la democracia como forma de gobierno, solo puede sobrevivir en un Estado pequeño. 
Según Charles Taylor (citado por Honneth ${ }^{33}$ ), en la obra de Montesquieu "se encuentra el origen de una noción de sociedad civil en la que las corporaciones legalmente legitimizadas de autogobierno público son las responsables de mediar constantemente entre la esfera social y el Estado". El filósofo Alemán Hegel describió a la "sociedad civil" como la esfera comercial donde la gente era considerada como individuos separados, cuyos intereses eran civiles y económicos, pero no políticos ni morales y se basaba en el propio interés de individual y particular que no podía ser reconciliado con una moralidad universal. Hegel consideró a la sociedad civil como la esfera de representación de intereses que no comprende al Estado. Hegel concluyó que el Estado es la autoridad moral final para los conflictos que surjan dentro del mismo ${ }^{34}$.

El concepto hegeliano de una sociedad civil burguesa adquiere vigor y se involucra en el espacio público en forma de opinión pública en las sociedades modernas. Las sociedades modernas tienen como características la diferenciación social, la secularización de la cultura política y un sistema político. Cuando estos ciudadanos convertidos en actores de la sociedad civil se preocupan por los problemas de la comunidad se dimensionan en la esfera pública y se expresan en una opinión como reconocimiento de que comparten intereses generales.

En el siglo XVIII, Adam Smith y David Hume hablaron de "sociedad civil" para referirse a la emergente clase burguesa surgida del comercio para protegerse de los señores feudales, de tal forma que el término fue aplicado al naciente sector comercial privado, por el que los individuos eran libres para desarrollar sus propios negocios

El Zivilgessellschaft que "evoca el republicanismo democrático de Tocqueville" y el Bürgerliche gesselschaft que se refiere a la estructura legal del "sistema de necesidades", tales como se conocen en la Filosofía del derecho de Hegel, son los conceptos alemanes que se acercan a la concepción de sociedad civil para referirse a todas las instituciones y organizaciones que preceden al Estado. La polisemia del concepto de sociedad civil muestra diferentes contenidos según la describa Tocqueville o algún autor actual. Tanto Mill como Tocqueville caracte-

\footnotetext{
${ }^{33}$ HONNETH, Axel. Op. cit.

${ }^{34}$ BRUYN, Severyn T. The moral economy. In: Review of Social Economy. V. LVII, n. 1, march 1999.
} 
rizan a la sociedad civil distinguiéndola del Estado-aparato, caracterización que es más relevante en Gramsci y que entran en contradicción

El concepto de sociedad civil, del Inglés civil society, tal como lo conceptualizó Adam Ferguson, se refiere a "Todas las instituciones y organizaciones civiles que preceden al Estado, ya que son la condición previa a cualquier resistencia por parte de los ciudadanos, contra la dictadura de la burocracia de partido." En este sentido, Thoreau ha dicho que los hombres reconocen el derecho a la revolución, como el derecho a rechazar la obediencia, lealtad y a resistir un gobierno cuando su tiranía e ineficiencia son insoportables ${ }^{35}$. El término anglosajón de civil society hace referencia más al concepto de sociedad civilizada que al de sociedad natural.

Marx ubica en la sociedad civil el espacio negativo de lo privado donde se desarrollan las relaciones económicas o materiales y en donde además, la familia representaba lo opuesto a la parte más organizada de la sociedad denominada Estado o sociedad política.

De acuerdo a Gramsci, la sociedad civil se constituye en relación con el Estado. Para Gramsci el concepto de la societé civile es equivalente a "esfera pública" o Bürgerliche Öffentlichkeit de Habermas ${ }^{36}$, definido como un "ámbito social en el que están incluidos todas las instituciones culturales dentro de las cuales se forma la opinión pública". El nivel de asociacionismo de los individuos de una comunidad y las formas de transmisión de las creencias (Gramsci) son las características orgánicas de la sociedad civil. Gramsci distingue la caracterización de la sociedad civil del Estado-aparato, los cuales entran en contradicción con intereses que pueden ser irreconciliables sobretodo cuando el Estado-aparato se apartan del bien social. Gramsci rescata a la sociedad civil de la base económica y la lleva a la superestructura y le da el lugar de la formación del poder ideológico diferente del poder político en sentido estricto y de los poderes de legitimación de la clase dominante.

Urquiza y Ulloa ${ }^{37}$ sintetizan la conceptualización moderna y contemporánea de la sociedad civil en su carácter relacional, señalando que "los modernos

${ }^{35}$ HONNETH, Axel. Op. cit.

${ }^{36}$ HABERMAS, Jürgen. Struggles for recognition in the Democratic Constitutional State, In: GUTMAN, A. Multiculturalism. Princeton: Princeton univ. Press, 1994.

${ }^{37}$ URQUIZA, Waldemar, ULLOA, Félix. Op. cit. 
establecen una cierta continuidad, porque cuando hablan de la sociedad civil aluden a un sedimento relacional de sana convivencia, tolerancia ideológica, búsqueda de intereses particulares y disfrute de los derechos individuales y sociales". De los contemporáneos señalan que "tienen un punto de convergencia al referir la sociedad civil como un substrato organizacional de carácter privado que ejerce una influencia especialmente económica e ideológica decisiva en toda la sociedad, para bien o para mal, dependiendo de sus propios intereses".

En la sociedad civil se involucran fuerzas que se contraponen en sus intereses irreconciliables, muchas de las veces. Urquiza y Ulloa ${ }^{38}$ hacen una distinción operativa al interior de la sociedad civil entre lo que denomina la "sociedad civil del capital" y la sociedad civil descapitalizada". Sin embargo, la caracterización dual de la sociedad civil en términos de quien tiene capital y no lo tiene es confusa sino se delimitan los sujetos, las instituciones que representan sus intereses y el espacio o esfera donde resuelven sus conflictos.

El concepto de "sociedad civil del capital" lo expresa como "el conjunto de individuos y organismos privados que controlan el gran capital, y que por tanto, poseen intereses comunes y guardan una mayor afinidad ideológica", mientras que la "sociedad civil descapitalizada está caracterizada por la no propiedad del capital y por situarse frente a él como una masa asalariada, y por tanto, por asumir o "deber asumir" una posición existencial de lucha contra la explotación y buscar una mayor participación de los beneficios del trabajo que garantice una adecuada sobrevivencia humana".

Así, la teoría dicotómica de la sociedad civil, intenta establecer "la línea divisoria entre la gran empresa unida a los altos dirigentes del Estado-aparato y la gran mayoría restante, mayoría que encierra potencialidades similares de cara al cambio social." La sociedad civil del capital puede guiar las acciones y manipular los comportamientos y voluntades de la sociedad civil descapitalizada. El Estado-aparato sigue una política de dualidad, mientras que con la sociedad civil capitalizada entra en procesos de negociación de políticas e intereses y resolución de conflictos, desprecia con trato diferenciado a la sociedad civil no capitalizada la cual es fácilmente manipulable para fines corporativos electorales.

\footnotetext{
${ }^{38}$ Idem.
} 
El problema es el carácter relacional del análisis que no es confiable. Por lo tanto, concluyen que la sociedad civil "comprende el conjunto de relaciones $\mathrm{y}$ acciones que generan los individuos, ya sea asociados o no asociados, cualificados por el hecho de estar desprovistos, por lo menos de forma expresa, de la autoridad que confiere el poder político que emana del Estado-aparato".

La emergencia de las organizaciones no gubernamentales en los decenios de 1980 y 1990 coinciden con en el mismo momento en que se liquidaba el bloque socialista y la URSS como una respuesta desde la sociedad civil, frente a las aberraciones estatistas que habían impregnado al grueso de la izquierda. La sociedad civil ha pasado por un largo periodo de transición para convertirse en el principal actor, protagonista de los cambios en todos los órdenes del tejido social, dejando atrás la abulia tradicional que le caracterizaba como un sujeto pasivo y manipulable. Sin embargo, no se regulan los procesos de transición la sociedad es amenazada de destrucción.

La globalización de los procesos económicos ha generado la globalización de la sociedad civil, mediante la creación de nuevas redes e instituciones que formulan agendas globales. Las organizaciones no gubernamentales activas y estructuradas en la sociedad civil se enlazan formando una red con el apoyo de las nuevas tecnologías de la información y la comunicación para promover acciones de resistencia frente a las instituciones que imponen los procesos de globalización del sistema económico capitalista.

La sociedad civil conjunta reivindicaciones de diferentes movimientos sociales que se oponen y resisten los procesos de globalización orientados por una hegemonía corporativa. Es decir, desde la base misma de la sociedad, se apoya la defensa de la ideología neoliberal y antiestatista, desde una falsa posición de izquierda que defiende a la sociedad civil y que conduce a procesos de despolitización y desmovilización de los grupos que pudieran expresar sus inconformidades y demandas contra el sistema neoliberal a través de movimientos sociales. A pesar de los procesos de globalización económica, si tiene que haber algún tipo de respuesta democrática a la ascendencia del neoliberalismo, entonces la transformación del Estado a través de los movimientos sociales queda como un camino válido ${ }^{39}$.

${ }^{39}$ MAY, Christopher. From international political economy to global political economy. The In- 
Sin embargo, la sociedad civil en el modelo neoliberal queda reducida a un conjunto de meros procedimientos que limitan la concepción de las instituciones políticas y su compromiso con el desarrollo humano. Las instituciones políticas determinan el tipo de relaciones de la sociedad política y la dinámica de la sociedad civil, que pueden ser de incertidumbre. En los procesos de institucionalización, las estructuras de la acción política de los actores gubernamentales y de la sociedad civil se sustentan en normas y valores que tienen su impacto motivacional y en la cohesión de los grupos sociales. El desarrollo actual de la sociedad civil ha sido motivo de diversos análisis. Según Bruyn (1999), los conservadores la denominan el "sector voluntario".

\section{Funciones de la sociedad civil}

El papel fundamental de la sociedad civil es constituirse en los agentes del cambio del cambio social mediante la promoción de la democracia y una mayor participación en los procesos de toma de decisiones públicas. El foco central de las organizaciones no gubernamentales y de la sociedad civil es restablecer el control democrático de las instituciones en las políticas públicas económicas, sociales y de bienestar, pero se pierde control social y rendición de cuentas cuando estos procesos están muy centralizados.

La sociedad civil se enfoca al entendimiento y a los diferentes modos conscientes y a las prácticas de la naturaleza comunitaria de las culturas y prácticas diarias de los ciudadanos, sus valores y creencias, etc., fuera de las instituciones del Estado y en donde las instituciones y entidades que la forman desarrollan sus actividades y funciones.

La incorporación de las organizaciones de la sociedad civil (OSC) en los procesos de formulación e implementación de las políticas públicas se establece mediante relaciones que son gobernadas por el "respeto a la independencia y autonomía de las OSC, por el reconocimiento de su identidad especial y por la transparencia y la imparcialidad en los tratos" según Martínez Nogueira ${ }^{40}$. La

ternational Political Economy Yearbook Series: an assessment. In: Political Geography, v. 16, n. 7, 1997, pp. 605-615.

${ }^{40}$ MARTINEZ NOGUERA, Roberto. Op. cit. 
ausencia de una cultura institucional impide el logro de mejores resultados, incluyendo la autonomía. Las organizaciones de la sociedad civil proyectan y despliegan la capacidad de la acción del Estado. Como una fuerza, la sociedad civil puede hacer rendir cuentas a políticos y burócratas. No obstante Finot ${ }^{41}$ concluyó que "sólo excepcionalmente se consiguió la participación de los ciudadanos en la gestión pública, además de en las elecciones".

Las actividades de la sociedad civil consolidan la democracia a partir de formas asociacionistas definidas por valores liberales. El fortalecimiento de la sociedad civil se logra a través de la participación ciudadana en los asuntos públicos y en el involucramiento ciudadano en los ámbitos de gestión pública local. De acuerdo a Martínez Nogueira ${ }^{42}$, la incorporación de la sociedad civil a las políticas públicas representa una forma para canalizar recursos sociales y capacidades porque se generan economías de escala, se reducen los costos de transacción y se establecen limitaciones a los comportamientos oportunistas. La formulación e implementación de las políticas públicas pueden aprovechar los recursos y capacidades de la sociedad civil a través de las organizaciones no gubernamentales.

La creación de espacios para la toma de decisiones mediante mecanismos de gobernabilidad que democráticamente informen del bienestar, de los principios de derechos humanos, del desarrollo sustentable y del desarrollo social es un rol importante de la sociedad civil. La sociedad civil tiene un papel preponderante para establecer y mantener la gobernabilidad a través de la asistencia a los gobiernos en la implementación de amplios objetivos sociales. Las políticas sociales no conseguirán sus objetivos sino se conceptualizan e implementan con una base fuerte de la sociedad civil. Las estrategias de reducción de la pobreza deben ser elaboradas por los propios gobiernos mediante la consulta a la sociedad civil y su involucramiento en la aplicación para garantizar los resultados.

Las transferencias de conocimientos y experiencias fortalecen a la sociedad civil y les otorga capacidad y autonomía para ejercer sus funciones en las nuevas formas de gobernabilidad. La autonomía de la sociedad civil se sustenta en las

${ }^{41}$ FINOT, Ivan. Elementos para una reorientación de las políticas de descentralización y particìpación en Amétrica Latina. In: Revista del CLAD Reforma y Democracia. N. 15, October 1999.

${ }^{42}$ MARTINEZ NOGUERA, Roberto. Op. cit. 
redes sociales que con base en la confianza y reciprocidad, despliegan la esfera pública. Este compendio heterogéneo de componentes que actúan en la esfera de la sociedad civil, de acuerdo a Murillo Castaño ${ }^{43}$, constituye un "modelo que valora la pluralidad y el respeto a las diferencias, culturales, étnicas y religiosas. Sin embargo, la ausencia de una cultura institucional impide el logro de mejores resultados, incluyendo la autonomía.

Sin embargo, las diferencias de la densidad de las organizaciones sociales también varían regionalmente ofreciendo diferentes niveles de oportunidades y posibilidades de organización, expresión y manifestación de los intereses de los individuos, por lo que se puede decir que tanto social como territorialmente, la sociedad civil es desigual. Existe una relación cercana entre el desarrollo de la sociedad civil, los movimientos sociales y el desarrollo democrático, para impulsar las formas democráticas en todos los ámbitos de la organización social. Nuevamente, el pensamiento de Habermas (1998) es claro:

"En el proceso de la globalización, la capacidad de cooperación de los egoístas racionales se encuentra rebasada. Las innovaciones institucionales no tienen lugar en sociedades - cuyas élites gubernamentales son capaces de tales iniciativas - si no encuentran antes la resonancia y el apoyo en las orientaciones valorativas reformadas de sus poblaciones. Por esta razón los primeros destinatarios de este proyecto no pueden ser los gobiernos, sino los movimientos sociales y las organizaciones no gubernamentales, es decir, los miembros activos de una sociedad civil que trasciende las fronteras nacionales. Sea como fuere, la idea nos lleva a pensar que la globalización de los mercados debe ser reglamentada por instancias políticas: las arduas relaciones entre la capacidad de cooperación de los regímenes políticos y la solidaridad civil universal (Weltbürgerliche Solidarität).

Una sociedad civil marginada no permite el acceso de los ciudadanos al mercado político ni al disfrute de los bienes públicos democráticos. Torres-Ri$\operatorname{vas}^{44}$, señala como riesgos negativos de las sociedades civiles, la debilidad de las asociaciones, la falta de autonomía y de defensa de los intereses y derechos del grupo y la legalidad de su existencia.

\footnotetext{
${ }^{43}$ MURILLO CASTAÑO. La organización de la sociedad civil: una alternative respecto a los partidos polticos? In: Biblioteca de Ideas. Instituto International de Governabilidad. http://www. iigov/pnud/biblioteca/documentos/docu0013.htm.
}

${ }^{44}$ TORRES-RIVAS. Op. cit. 


\section{La emergente sociedad civil en \\ Latinoamérica}

En América Latina, el Estado "remanente"45 del modelo de Estado de Bienestar no consolidado fue incapaz de dar soluciones a las crecientes demandas de bienestar, por lo que se crea un vacío que empieza a ser cubierto por la emergente sociedad civil que empieza a jugar un importante papel.

El programa político de gobernabilidad democrática propuesto para los Estados latinoamericanos a finales de los noventa, se orienta a alcanzar la estabilidad de las instituciones políticas y sociales a través del fortalecimiento de las organizaciones intermedias entre el Estado y la sociedad civil, tales como los partidos políticos, con capacidad para eliminar las barreras existentes entre la sociedad civil y el Estado. Este programa de gobernabilidad busca la promoción de la política democrática orientada a la formación de una opinión pública mediante una regeneración de la vida ciudadana capaz de encausar los intereses y derechos de la sociedad civil que el mismo Estado reconoce.

Los elementos del Programa de Desarrollo de las Naciones Unidas para la promoción de la gobernabilidad y la democracia en Latinoamérica comprenden la consolidación de la gobernabilidad democrática más allá de las elecciones, el fortalecimiento de las instituciones de la gobernabilidad democrática, promoción del Estado de Derecho mediante la separación de poderes, el apoyo a la sociedad civil con atención particularizada a las organizaciones no gubernamentales, grupos de educación cívica, centro de estudio y desarrollo de políticas, medios de comunicación independientes y sindicatos (Santiso, 2002). El Banco Mundial trabaja con los países que piden su ayuda sobre la base de un proceso participativo para asegurarse de la buena voluntad de los poderes públicos y la colaboración de la sociedad civil. Al fin de este proceso un programa de acción es establecido y fue propuesto al país demandante.

Los factores estratégicos para promover el desarrollo de los pueblos latinoamericanos tienen que ver con la reforma institucional y con la promoción del papel activo que tiene que desempeñar las organizaciones sociales y la misma sociedad civil. Chile basó su poder en mantener la distancia social de la sociedad

\footnotetext{
${ }^{45}$ MARTINEZ NOGUERA, Roberto. Op. cit.
} 
civil y reprimiendo a la oposición, mientras que en México, el Estado buscó perpetuar su hegemonía abarcando a la sociedad entera a través de redes complejas de patronazgo.

El régimen mexicano nació de una acción revolucionaria contra una dictadura aristocrática que puso atención a las demandas de los más necesitados y suavemente cooptó o reprimió a sus disidentes. Según Razcón ${ }^{46}$, en México "la sociedad civil quedó en manos de las iglesias, las cuales son un ejército organizado y jerarquizado, cuya hegemonía política ha crecido, gracias al debilitamiento de los partidos progresistas y laicos y al cariz que ha tomando la sociedad civil en su dispersión intrínseca. Las ONG y fundaciones se quedaron con miles de cuadros y activistas agotados por la burocratización y el sectarismo de sus organizaciones, que fueron la base y el motor que construyeron los grandes movimientos sociales, sindicales y campesinos de finales del siglo xx."

\section{Análisis de los retos de la sociedad civil}

En las organizaciones de la sociedad civil descansa un potencial de cambio económico, político y social. Las acciones y las formas operativas de una sociedad civil pueden abrir, profundizar y ampliar los procesos de cambio para la institucionalización de una cultura democrática sustentada en un código de principios democráticos. La participación de las asociaciones en la sociedad civil representa un potencial democrático que une los movimientos populares al sistema político, estabilizando y fortaleciendo sus instituciones. Así la participación política es un factor que facilita el desarrollo democrático de las sociedades. El desarrollo democrático de las sociedades impulsa la sociedad civil. A largo plazo, aunque no está exenta de riesgos, la sociedad civil tiene la tendencia a consolidar la democracia, más que a fundarla, aunque este es un planteamiento cuestionable. El impacto que tiene la sociedad civil para resolver los grandes problemas contemporáneos de una sociedad más democrática, todavía está por verse.

La globalización se perpetua en los contenidos de la información y la comunicación excluyendo a más individuos que quedan fuera de los beneficios de la

${ }^{46}$ RAZCÓN, Marco. Op. cit. 
nueva cultura e identidad global. Este hecho destaca la importancia de fomentar lazos de solidaridad, desde el Estado o desde la propia sociedad civil. De acuerdo a Gramsci, la sociedad civil se constituye en relación con el Estado. Es decir, no es posible transformar una sociedad y el Estado sin una idea o proyecto global sobre la economía, el Estado, las leyes; y la sociedad civil requiere instrumentos propios para organizarse y organizar a todos los estratos de la sociedad".

En una sociedad más desarrollada se fortalecen el Estado, el mercado y la sociedad civil, como instrumentos del desarrollo mismo. La autonomía de la sociedad civil frente al Estado y el mercado debe sostenerse a fin de que prevalezca una relación de interdependencia. La autonomía de la sociedad civil necesita fortalecerse para convertirse en un verdadero interlocutor de los agravios del Estado. Autonomía e interdependencia adquieren un carácter coexistente. E1 mayor reto que enfrenta la sociedad civil es el desarrollo de las facultades para administrar su propia regulación específica de derechos y obligaciones. Un instrumento de las organizaciones de la sociedad civil para la construcción de la cultura de rendición de cuentas es la inclusión de mecanismos de monitoreo y auditoria social.

El Estado de Derecho, el fortalecimiento de la sociedad civil y el desarrollo de la capacidad de gobernabilidad son requerimientos del Buen gobierno porque contribuyen a la ampliación y profundización del espacio público y al establecimiento de mecanismos de control social sobre los recursos públicos. Todavía más, se debe dar lugar a un Estado ampliado donde las instituciones de las esferas propias de la sociedad civil y del Estado confluyan en formas de gobernabilidad que propicien la colaboración. Todavía es un reto involucrar a las instituciones del Estado, el sector privado y la sociedad civil para la provisión de los bienes sociales.

Es necesario transformar el marco jurídico en que funcionan las jurisdicciones internacionales con el objeto de permitir a la sociedad civil (ciudadanos y sus asociaciones) actuar ante la justicia en las jurisdicciones nacionales como en el escalón internacional contra los Estados, las empresas o las organizaciones internacionales. La sociedad civil global debe asegurar la igualdad cívica universal caracterizada por el respeto a los derechos humanos como condición de desarrollo de la humanidad. 
El aumento de la frecuencia de las crisis financieras requiere de serias reformas a la arquitectura del sistema financiero mundial en la que también participen las organizaciones de la sociedad civil de los países en desarrollo para diversificar la formulación de políticas. La formulación e implementación de políticas de participación equitativa deben promover procesos de negociación de los intereses de las diferentes asociaciones y agrupaciones mediante la construcción de nuevas formas de la sociedad civil, con el fin de que se fortalezcan como uno de los pilares del desarrollo social y humano.

La responsabilidad social corporativa debe fortalecerse y monitorear su cumplimiento. Las organizaciones de la sociedad civil tienden a reemplazar las funciones que tienen los partidos políticos como canales de expresión de inconformidades y descontento, dando lugar a los nuevos movimientos sociales que luchan por lograr poner en la agenda la nueva cuestión social. La reforma de los partidos políticos deben abrirse a los cambios que experimenta la sociedad civil al influjo de los procesos de globalización, abandonando esquemas corporativistas rígidos, con la posibilidad de ofrecer elecciones significativas.

La idea de que emergerán instituciones en el ámbito global que desarrollen las funciones de los partidos políticos, parece ser irreal, a pesar de la necesidad de que existan políticos que sirvan de intermediarios entre la ciudadanía global y los formuladores e implementadores de las políticas. El fortalecimiento de la ciudadanía como participación efectiva de los actores sociales en los asuntos públicos es esencial para enfrentar el deterioro de la cohesión social. En efecto, todas las sociedades de la región vienen experimentando, con mayor o menor intensidad, una pérdida de sentido de pertenencia de las personas a la sociedad, de identidad con propósitos colectivos y de desarrollo de lazos de solidaridad. Este hecho destaca la importancia de fomentar lazos de solidaridad, desde el Estado o desde la propia sociedad civil.

El nuevo acercamiento a la política social debe examinar las capacidades de los gobiernos locales, estatales y nacionales, las organizaciones de la sociedad civil para introducir formas participativas de administración social de los sistemas de políticas sociales. Lo que es necesario, es cambiar los términos de la política social a través del establecimiento de un pacto político-social para subordinar el interés individual al interés de la sociedad. Este pacto debe ser el resultado de acuerdos entre partidos políticos y organizaciones de la sociedad 
civil de carácter asistencial social, a partir del desarrollo y la participación solidaria de la organización comunitaria de la sociedad civil.

El gobierno local requiere de una sociedad civil asentada en un territorio con un conjunto de valores y normas que sustentan la identidad con un sistema político que le proporciona el poder capaz suficiente para la transformación de procesos de generación de bienestar y riqueza. El gobierno local asegura la mediación entre el poder hegemónico del Estado y la sociedad civil, facilita los intercambios e integra las acciones entre los diferentes actores. El gobierno local debe movilizar a la sociedad civil como una nueva forma de interrelacionar al Estado con la sociedad promoviendo mediante procesos democráticos la descentralización de los servicios, con fundamento en el principio de cercanía que enuncia que las decisiones sean tomadas lo más cercano posible a la población involucrada. 